\title{
RESEARCH
}

Open Access

\section{Effects of hypertonic saline versus mannitol in patients with traumatic brain injury in prehospital, emergency department, and intensive care unit settings: a systematic review and meta-analysis}

Yukari Miyoshi ${ }^{1}$, Yutaka Kondo ${ }^{1 *}$ (D) Hidetaka Suzuki ${ }^{2}$, Tatsuma Fukuda ${ }^{3}$, Hideto Yasuda ${ }^{4}$, Shoji Yokobori ${ }^{5}$ and for the Japan Resuscitation Council (JRC) Neuroresuscitation Task Force and the Guidelines Editorial Committee

\begin{abstract}
Background: Intracranial pressure control has long been recognized as an important requirement for patients with severe traumatic brain injury. Hypertonic saline has drawn attention as an alternative to mannitol in this setting. The aim of this study was to assess the effects of hypertonic saline versus mannitol on clinical outcomes in patients with traumatic brain injury in prehospital, emergency department, and intensive care unit settings by systematically reviewing the literature and synthesizing the evidence from randomized controlled trials.

Methods: We searched the MEDLINE database, the Cochrane Central Register of Controlled Trials, and the Igaku Chuo Zasshi (ICHUSHI) Web database with no date restrictions. We selected randomized controlled trials in which the clinical outcomes of adult patients with traumatic brain injury were compared between hypertonic saline and mannitol strategies. Two investigators independently screened the search results and conducted the data extraction. The primary outcome was all-cause mortality. The secondary outcomes were 90-day and 180-day mortality, good neurological outcomes, reduction in intracranial pressure, and serum sodium level. Random effects estimators with weights calculated by the inverse variance method were used to determine the pooled risk ratios.

(Continued on next page)
\end{abstract}

\footnotetext{
* Correspondence: kondokondou2000@yahoo.co.jp

'Department of Emergency and Critical care Medicine, Juntendo University Urayasu Hospital, 2-1-1 Tomioka, Urayasu, Chiba 279-0021, Japan

Full list of author information is available at the end of the article
}

(c) The Author(s). 2020 Open Access This article is licensed under a Creative Commons Attribution 4.0 International License, which permits use, sharing, adaptation, distribution and reproduction in any medium or format, as long as you give appropriate credit to the original author(s) and the source, provide a link to the Creative Commons licence, and indicate if changes were made. The images or other third party material in this article are included in the article's Creative Commons licence, unless indicated otherwise in a credit line to the material. If material is not included in the article's Creative Commons licence and your intended use is not permitted by statutory regulation or exceeds the permitted use, you will need to obtain permission directly from the copyright holder. To view a copy of this licence, visit http://creativecommons.org/licenses/by/4.0/. The Creative Commons Public Domain Dedication waiver (http://creativecommons.org/publicdomain/zero/1.0/) applies to the data made available in this article, unless otherwise stated in a credit line to the data. 
(Continued from previous page)

Results: A total of 125 patients from four randomized trials were included, and all the studies were conducted in the intensive care unit. Among 105 patients from three trials that evaluated the primary outcome, 50 patients were assigned to the hypertonic saline group and 55 patients were assigned to the mannitol group. During the observation period, death was observed for 16 patients in the hypertonic saline group (32.0\%) and 21 patients in the mannitol group (38.2\%). The risks were not significant between the two infusion strategies (pooled risk ratio, 0.82; 95\% confidence interval, 0.49-1.37). There were also no significant differences between the two groups in the other secondary outcomes. However, the certainty of the evidence was rated very low for all outcomes.

Conclusions: Our findings revealed no significant difference in the all-cause mortality rates between patients receiving hypertonic saline or mannitol to control intracranial pressure. Further investigation is warranted because we only included a limited number of studies

Keywords: Traumatic brain injury, Hypertonic saline, Mannitol, Prognosis, Trauma

\section{Background}

Intracranial pressure (ICP) control has long been recognized as an important requirement for patients with severe traumatic brain injury (TBI) [1]. Hypertonic solutions effectively reduce the patient's ICP without brain perfusion impairment [2]. Although mannitol has been the recommended first-line osmotic agent in this setting for years, there are concerns that its use may lead to hypotension, especially in hypovolemic patients, as well as a rebound phenomenon with increased ICP, along with renal toxicity due to increases in serum osmolality $[3,4]$. Thus, hypertonic saline (HS) has recently drawn attention as an alternative to mannitol and has been found to be more effective than mannitol for reducing ICP in TBI cases [5-7]. However, hypertonic saline is also associated with potential adverse effects, such as pontine myelinolysis [8]. Moreover, few clinical studies have focused on TBIrelated outcomes, such as patient survival and long-term beneficial effects, and there is a lack of clarity regarding which HS is the most suitable for use in prehospital, emergency department, and intensive care unit (ICU) settings. Therefore, we aimed to assess the effects of HS versus mannitol strategies on TBI-related clinical outcomes.

\section{Material and methods}

\section{Data sources and search strategies}

The Japan Resuscitation Council (JRC) Neuroresuscitation Task Force and Guidelines Editorial Committee were established in 2020 by the Japan Society of Neuroemergencies and Critical Care, the Japanese Society of Intensive Care Medicine, and the Japan Society of Neurosurgical Emergency. The JRC Neuroresuscitation Task Force set clinically relevant questions for this systematic review.

To identify eligible trials, we searched the MEDLINE database via PubMed, the Cochrane Central Register of Controlled Trials, and the Igaku Chuo Zasshi (ICHUSHI) Web database [9]. The search was performed on October
1,2019 , and was not restricted by publication status, date of publication, or sample size, although only reports published in English and Japanese were included. The search terms were presented in Supplemental file 1. Systematic review and meta-analysis were conducted in accordance with the PRISMA guidelines [10], and was registered in the UMIN Clinical Trials Registry (ID UMIN000040184).

\section{Study selection}

The titles and abstracts of the search results were retrieved from the databases. After the exclusion of duplicate studies, two investigators (YM and HS) independently screened the titles and abstracts for potential eligibility. In the case of disagreement between reviewers, the full-text report was used to determine study eligibility. Disagreements were resolved by consensus, although a third reviewer (TF) was consulted if consensus could not be reached. The full texts of potentially eligible articles were independently reviewed by two investigators (YM and HS), and a final decision regarding eligible studies was made after a discussion involving all authors and the resolution of disagreements by consensus.

We identified randomized controlled trials (RCT) for inclusion based on the research question and according to the PICO model (participants, interventions, comparisons and outcomes): participants, adults ( $\geq 15$ years old) with TBI; interventions, administration of HS in prehospital, emergency department, and ICU settings; comparisons, administration of non-HS ICP-lowering agents in the same situation; and outcomes, the primary outcome was all-cause mortality.

\section{Data extraction}

Data extraction was conducted independently by two investigators (YM and HS), with consensus used to resolve any disagreements. The extracted data included author, year of publication, country, study design, number of 
study participants, patient demographics, outcome measures, and inclusion and exclusion criteria.

\section{Study endpoints}

We set all-cause mortality during the observation period as the primary outcome. The secondary outcomes were 90-day and 180-day mortality, good neurological outcomes, decline in ICP, and serum sodium level. According to the Grading of Recommendations Assessment, Development and Evaluation (GRADE), the primary outcome was defined a "critical" outcome and secondary outcomes as "important" or "critical" outcomes [11].

\section{Assessment of methodological quality: risk of bias assessment and GRADE approach}

We adapted the Cochrane risk of bias tool to assess the quality of the included studies [12]. Each study was assessed for (1) random sequence generation (selection bias), (2) allocation concealment (selection bias), (3) blinding of participants and staff (performance bias), (4) blinding of related outcome assessments (detection bias), (5) true intention-to-treat analysis (attrition bias), (6) incomplete outcome data (attribution bias), (7) selective reporting (reporting bias), (8) early trial withdrawal bias, and (9) other sources of bias. We classified the studies as having a low, intermediate, or high risk of bias in each domain. In addition, we graded the quality of evidence of each finding based on the criteria established by the GRADE working group [11]. The quality of study methodology was independently classified by two investigators (YM and $\mathrm{HS}$ ) as being high, intermediate, low, or very low, based on the study design, risk of bias, indirectness, inconsistency, imprecision, and

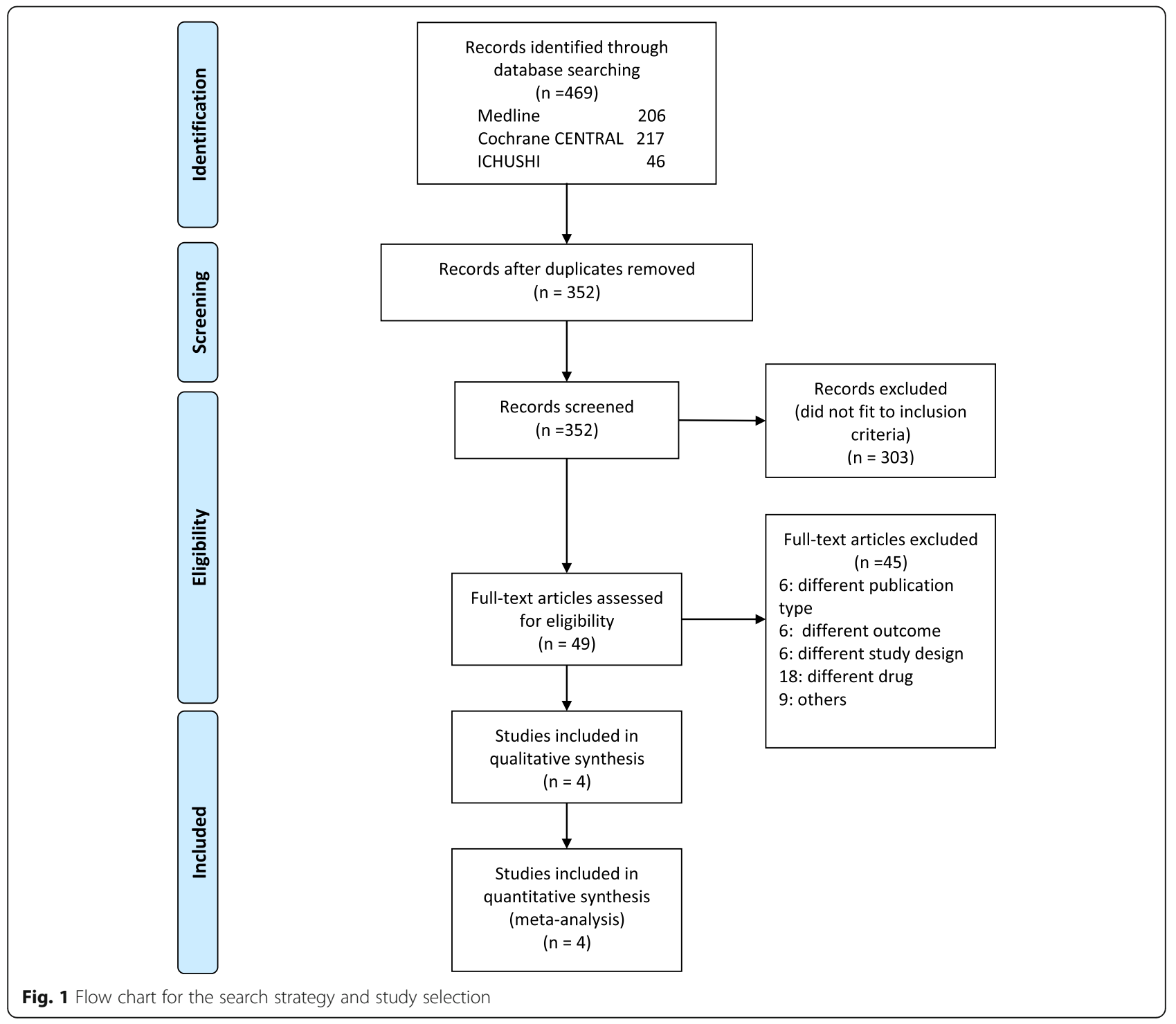


publication bias. Publication bias was assessed visually using a funnel plot.

\section{Statistical analysis}

We pooled the eligible patients for each outcome and calculated the risk ratios (RRs) and corresponding 95\% confidence intervals (CIs) using the Der Simonian-Laird random effects model. Weights were calculated by the inverse variance method for mortality and neurological outcomes, while the mean difference was used for the analyses of decline in ICP and serum sodium levels. We evaluated inter-study heterogeneity using the estimated Cochrane chi-squared test, Tau ${ }^{2}$, and $I^{2}$ statistics $\left(I^{2}>\right.$ $50 \%$ indicated severe heterogeneity). We applied unadjusted $p$ values to assess significance, with cut-offs for two-tailed $p$ values of 0.05 for hypothesis testing and 0.1 for heterogeneity testing. All statistical analyses were performed using Review Manager software (Cochrane systematic review software, version 5.3.5 for Windows; The Nordic Cochrane Centre, the Cochrane Collaboration, Copenhagen, Denmark).

\section{Results}

\section{Search results}

We identified 352 studies from the electronic databases after eliminating duplicates, although only 49 studies were assessed for eligibility based on the titles and abstracts. After a review of the full-text articles, 45 studies were excluded because of the study design, intervention, outcome, or data only being available in the abstract, despite the corresponding authors being contacted. Thus, four RCTs were included in the meta-analysis (Fig. 1).

\section{Study characteristics}

We analyzed a total of 125 patients from the four RCTs that were reported by Vialet et al. in 2003 [13], Francony et al. in 2008 [14], Cottenceau et al. in 2011 [15], and Jagannatha et al. in 2016 [16] (Table 1). Among 105 patients from three RCTs that evaluated the primary outcome $[13,15,16], 50$ patients were randomly assigned to the HS group and 55 patients were randomly assigned to the mannitol

Table 1 Baseline characteristics of eligible studies

\begin{tabular}{|c|c|c|c|c|c|c|c|c|}
\hline Study & $\begin{array}{l}\text { Type of } \\
\text { study }\end{array}$ & Country & $\begin{array}{l}\text { Total number } \\
\text { of patients }(n)\end{array}$ & Intervention & $\begin{array}{l}\text { Neurological state } \\
\text { on admission }\end{array}$ & $\begin{array}{l}\text { Age, years } \\
(\text { mean } \pm S D)\end{array}$ & $\begin{array}{l}\text { Gender, male/ } \\
\text { female }\end{array}$ & Inclusion criteria \\
\hline $\begin{array}{l}\text { Vialet } \\
\text { et al. [13] }\end{array}$ & $\mathrm{RCT}$ & France & 20 & $\begin{array}{l}\text { Group } 1(n=10) \text {, } \\
7.5 \% \mathrm{HS}, 2 \mathrm{ml} / \mathrm{kg} ; \\
\text { group } 2(n=10) \\
20 \% \text { mannitol, } \\
2 \mathrm{ml} / \mathrm{kg}\end{array}$ & $\begin{array}{l}\text { Group 1, } 4.1 \pm 1.6 \\
\text { group 2, } 5.4 \pm 2.8 \\
(\text { GOS mean } \pm S D)\end{array}$ & $\begin{array}{l}\text { Group 1, } 35.0 \pm 18 \\
\text { group 2, } 30.8 \pm 19\end{array}$ & $\begin{array}{l}\text { Group 1, 5/5; } \\
\text { group 2, 4/6 }\end{array}$ & $\begin{array}{l}\text { TBI patients with } \\
\text { informed consent } \\
\text { from the closest } \\
\text { relative who have } \\
\text { persistent coma } \\
\text { requiring ICP } \\
\text { monitoring and } \\
\text { infusion of an } \\
\text { osmotic agent to } \\
\text { correct refractory } \\
\text { episodes of ICP } \\
\text { that are resistant } \\
\text { to standard } \\
\text { modes of therapy }\end{array}$ \\
\hline $\begin{array}{l}\text { Francony } \\
\text { et al. [14] }\end{array}$ & $\mathrm{RCT}$ & France & 20 & $\begin{array}{l}\text { Group } 1(n=10) \text {, } \\
7.45 \% \mathrm{HS}, 100 \mathrm{ml} \text {; } \\
\text { group } 2(n=10) \text {, } \\
20 \% \mathrm{mannitol}, \\
231 \mathrm{ml}\end{array}$ & $\begin{array}{l}\text { Group 1, } 7 \pm 2 \\
\text { group 2, } 8 \pm 2 \\
(\text { GCS mean } \pm \text { SD) }\end{array}$ & $\begin{array}{l}\text { Group 1, } 37.0 \pm 16 \\
\text { group 2, } 43.0 \pm 11\end{array}$ & $\begin{array}{l}\text { Group 1, 9/1; } \\
\text { group 2, } 7 / 1\end{array}$ & $\begin{array}{l}\text { Aged } \geq 18 \text { years } \\
\text { and had sustained } \\
\text { elevated ICP of } \\
>20 \mathrm{mmHg} \text { for } \\
>10 \text { mins, not } \\
\text { related to } \\
\text { procedural pain. }\end{array}$ \\
\hline $\begin{array}{l}\text { Cottenceau } \\
\text { et al. [15] }\end{array}$ & $\mathrm{RCT}$ & $\begin{array}{l}\text { France, } \\
\text { Israel }\end{array}$ & 56 & $\begin{array}{l}\text { Group } 1(n=22) \text {, } \\
7.5 \% \mathrm{HS}, 2 \mathrm{ml} / \mathrm{kg} ; \\
\text { group } 2(n=25) \\
20 \% \text { mannitol, } \\
4 \mathrm{ml} / \mathrm{kg}\end{array}$ & $\begin{array}{l}\text { Group 1, } 5 \text { (4-7); } \\
\text { group 2, } 7 \text { (5-8) } \\
\text { (GCS median with } \\
\text { lower and upper) }\end{array}$ & $\begin{array}{l}\text { Group 1, } 42.7 \pm 19.9 \\
\text { group 2, } 36.1 \pm 16.8\end{array}$ & Not available & $\begin{array}{l}\text { TBI severe enough } \\
\text { to justify ICP } \\
\text { monitoring and } \\
\text { mechanical } \\
\text { ventilation under } \\
\text { sedation, with a } \\
\text { GCS of } \leq 8 \text { at the } \\
\text { time of admission }\end{array}$ \\
\hline $\begin{array}{l}\text { Jagannatha } \\
\text { et al. [16] }\end{array}$ & $\mathrm{RCT}$ & India & 38 & $\begin{array}{l}\text { Group } 1(n=18) \text {, } \\
3 \% \mathrm{HS}, 2.5 \mathrm{ml} / \mathrm{kg} ; \\
\text { group } 2(n=20) \text {, } \\
20 \% \text { mannitol, } \\
2.5 \mathrm{ml} / \mathrm{kg}\end{array}$ & $\begin{array}{l}\text { Group 1, } 4 \text { (4-5); } \\
\text { group 2, } 5 \text { (4-6) } \\
\text { (GCS median with } \\
\text { lower and upper) }\end{array}$ & $\begin{array}{l}\text { Group 1, } 27.0 \pm 8 \\
\text { group 2, } 31.0 \pm 13\end{array}$ & $\begin{array}{l}\text { Group 1, 16/2; } \\
\text { group 2, 18/2 }\end{array}$ & $\begin{array}{l}\text { Patients with severe } \\
\text { TBI aged between } \\
15 \text { and } 70 \text { years }\end{array}$ \\
\hline
\end{tabular}

$R C T$ randomized control trial, $H S$ hypertonic saline, GOS Glasgow outcome scale, GCS Glasgow coma scale, SD standard deviation, ICP intracranial pressure, $T B I$ traumatic brain injury, Group 1 HS group, Group 2 mannitol group 


\begin{tabular}{|c|c|c|c|c|c|c|c|c|c|}
\hline & Study or Subgroup & $\begin{array}{r}\text { HS } \\
\text { Events }\end{array}$ & Total & \multicolumn{2}{|c|}{ Mannitol } & Weight & $\begin{array}{c}\text { Risk Ratio } \\
\text { IV, Random, } 95 \% \mathrm{Cl}\end{array}$ & Year & $\begin{array}{c}\text { Risk Ratio } \\
\text { IV, Random, } 95 \% \mathrm{Cl} \\
\end{array}$ \\
\hline & Vialet 2003 & 4 & 10 & 5 & 10 & $28.1 \%$ & $0.80[0.30,2.13]$ & 2003 & $\longrightarrow$ \\
\hline & Cottenceau 2011 & 6 & 22 & 6 & 25 & $28.3 \%$ & $1.14[0.43,3.02]$ & 2011 & $=$ \\
\hline & Jagannatha 2016 & 6 & 18 & 10 & 20 & $43.6 \%$ & $0.67[0.30,1.46]$ & 2016 & $\rightarrow-$ \\
\hline & Total $(95 \% \mathrm{Cl})$ & & 50 & & 55 & $100.0 \%$ & $0.82[0.49,1.37]$ & & \\
\hline & Total events & 16 & & 21 & & & & & \\
\hline & $\begin{array}{l}\text { Heterogeneity: Tau }{ }^{2}= \\
\text { Test for overall effect: }\end{array}$ & $\begin{array}{l}0.00 ; \mathrm{Chi}^{2} \\
Z=0.77\end{array}$ & $\begin{array}{l}P^{2}=0.70 \\
P=0.4\end{array}$ & $\begin{array}{l}0, d f=2( \\
44)\end{array}$ & $(P=0.7$ & 1) $; i^{2}=0 x$ & & 0.01 & $\begin{array}{cccc}1 & 1 \\
0.1 & 1 & 10 & 100 \\
\text { Favours [HSI] } & \text { Favours [Mannitol] }\end{array}$ \\
\hline
\end{tabular}

group. The study by Francony et al. was not considered for the primary outcome because it only evaluated ICP reductions. Only one trial had a multicenter design (the study by Vialet et al. [13] included two different intensive care units in two different university hospitals from two different countries). Participants in the study by Francony et al. included some stroke patients (HS group, 2/10 patients [20\%]; mannitol group, $1 / 10$ patients [10\%]), while the other studies only included TBI patients.

\section{Outcomes}

The forest plot of the primary outcomes is shown in Fig. 2. During the observation period, death was observed for 16 of 50 patients in the HS group (32.0\%) and 21 of 55 patients in the mannitol group (38.2\%). The difference in risk was not significant between the two infusion strategies (pooled RR, 0.82 [95\% CI, 0.49-1.37]) (Fig. 2). The evaluation of 90-day mortality only included two RCTs $[13,16]$ and the evaluation of 180-day mortality also only included two RCTs $[15,16]$. Similar to the result for all-cause mortality, there were no significant differences between the HS and mannitol groups in the 90-day mortality rate (pooled RR, 0.54 [95\% CI, 0.23-1.27]) or the 180-day mortality rate $(0.82$ [95\% CI, $0.45-$ 1.52]) (Supplemental file 2). The number of patients with good neurological outcomes tended to be higher in the mannitol group than in the HS group, although the difference was not significant (pooled RR, 1.06 [95\% CI, 0.77-1.47]) (Fig. 3). Moreover, there were no significant differences between the groups in the reductions of ICP and serum sodium levels (Figs. 4 and 5).

\section{Heterogeneity}

For the primary outcome (all-cause mortality), no significant heterogeneity was observed among the studies $\left(I^{2}=0 \%, X^{2}=0.7, p=0.71\right)$ (Fig. 2). The heterogeneity evaluations for the other outcomes are described in Supplemental file 2.

\section{Publication bias, risk of bias, and quality of evidence}

We also analyzed the presence of publication bias (Fig. 6, Supplemental file 3). A visual inspection of the funnel plot revealed no asymmetry for all-cause mortality. The blinding of participants and personnel was categorized as being associated with a high or an unknown risk of bias in three RCTs due to the nature of the intervention (Fig. 7). The quality of the evidence was rated as very low for the effect of HS on the primary outcomes, with the grade lowered by 3 points due to the risk of biases in blinding and selective reporting, imprecision owing to the small sample sizes, and indirectness due to only ICU settings. The evidence summary is detailed in Table 2.

\section{Discussion}

This study assessed the effects of HS versus mannitol on clinical outcomes in TBI patients. There are few systematic reviews and meta-analyses of RCTs to compare the mortality rates associated with these two strategies [17, 18]. Our meta-analysis revealed that the HS and mannitol strategies were not statistically different in terms of

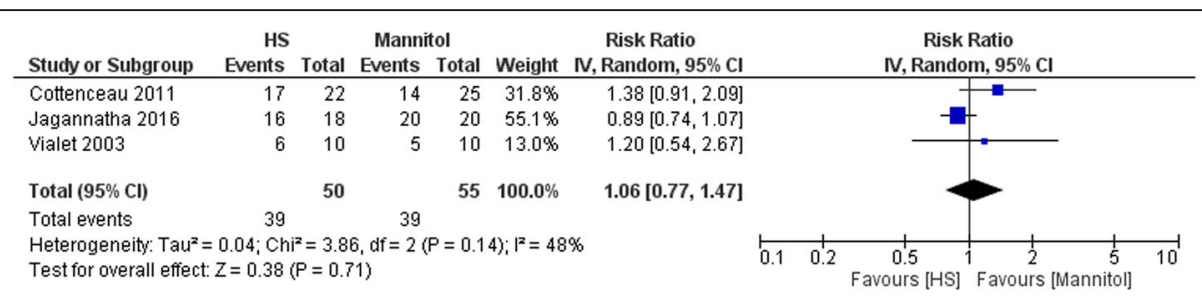

Fig. 3 Forest plot comparing the rates of good neurological outcomes between the HS and mannitol groups. HS, hypertonic saline; IV, Inverse variance; $\mathrm{Cl}$, confidence interval 


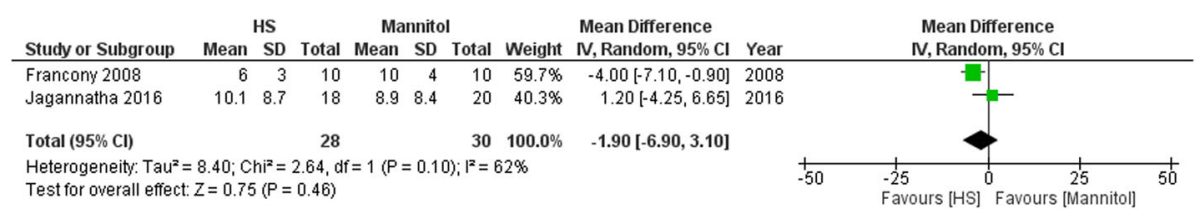

Fig. 4 Forest plot comparing the declines in the intracranial pressure between the HS and mannitol groups. HS, hypertonic saline; SD, standard deviation; IV, Inverse variance; $\mathrm{Cl}$, confidence interval

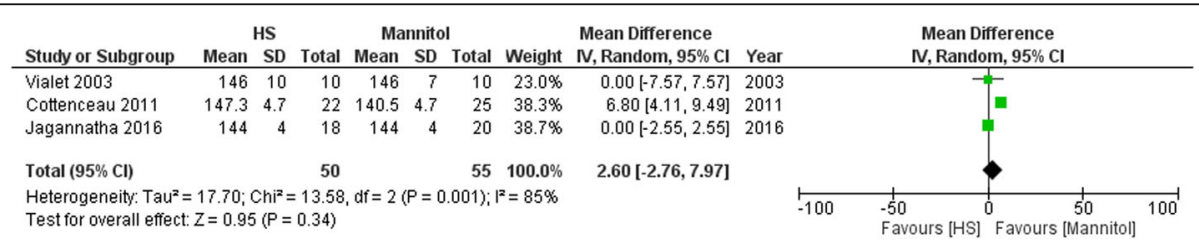

Fig. 5 Forest plot comparing the serum sodium levels between the HS and mannitol groups. HS, hypertonic saline; SD, standard deviation; IV, Inverse variance; $\mathrm{Cl}$, confidence interval



Fig. 6 Funnel plot of the three studies included in the meta-analysis of the all-cause mortality. HS, hypertonic saline; SE, standard error; RR, risk ratio 


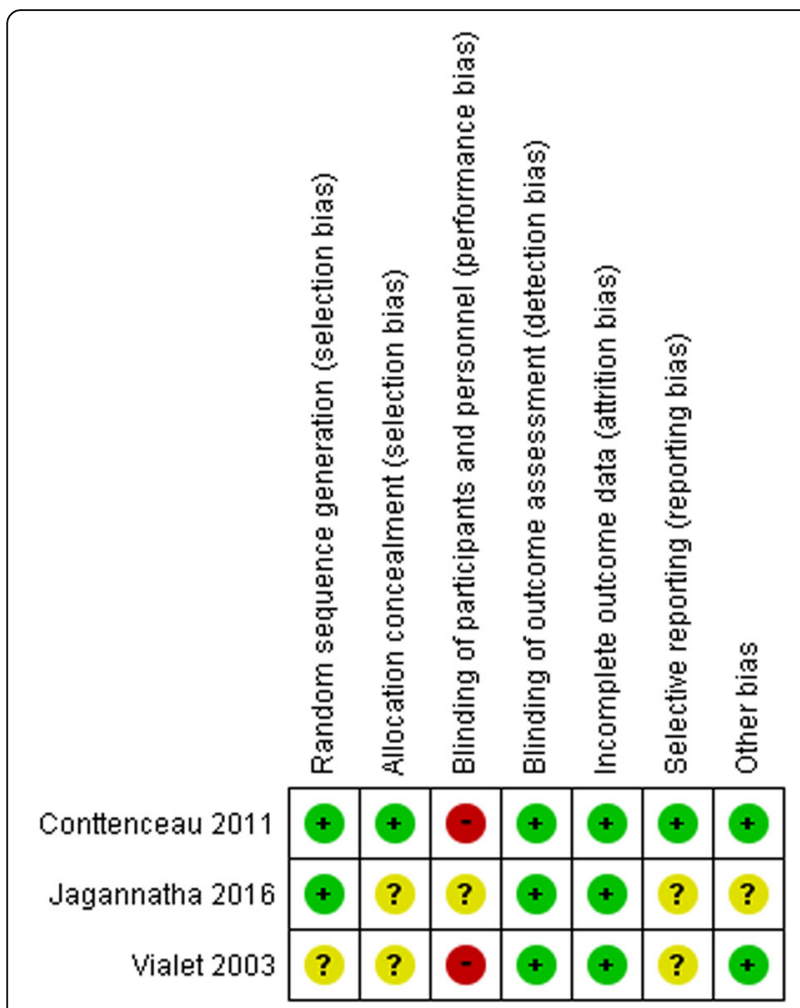

Fig. 7 Risk-of-bias summary for the included studies

improved clinical outcomes and mortality reductions in TBI patients. However, a large RCT is needed to address this issue, as the included studies had numerous limitations, including differences in the clinical setting at the time of infusion, dosage details, and small sample sizes (Table 1).

In patients with brain injury, ICP is a more powerful predictor of neurological deterioration than cerebral perfusion pressure [19]. Farahvar et al. [20] reported a decrease in the mortality values of patients who responded to ICP-lowering treatment from a large prospectively collected database. Although not entirely patientcentered as an outcome measure, ICP has been used as a prognostic indicator for determining the optimal HS type in some studies. A systematic review revealed that
HS and mannitol effectively reduced ICP after TBI [17]. However, a retrospective study of the Brain Trauma Foundation TBI-trac New York State database revealed no significant difference between the HS and mannitol groups in the 2-week mortality rates, although HS was more effective for reducing the cumulative ICP, the daily ICP, and the length of ICU stay [21]. This study also revealed no significant differences between the two groups in terms of mortality and neurological prognosis, which may suggest that HS and mannitol do not have significantly different effects on the clinical outcomes of TBI patients.

Conflicting results were seen between recent metaanalysis [22, 23] and ours. Our results could not show the significant differences of ICP between HS and mannitol whereas two previous meta-analyses [22, 23] showed significant ICP reduction by HS. The current meta-analysis included only two RCTs because we strictly selected eligible studies. We excluded two RCTs $[6,24]$, which were included in previous meta-analyses; a study reported by Patil did not meet our inclusion criteria and we could not get standard deviation information of ICP [6]. A study reported by Sakellaridis was event based, and the same patients participated in both arms of the treatments [24]. Strict inclusion criteria may become statistically under power. However, if we widely accepted many studies, more studies that are heterogeneous would be included. A guideline suggested using HS over mannitol [25] for the initial management of elevated ICP or cerebral edema for TBI patients although the level of evidence was low. Further studies are necessary to ascertain this claim.

Our results also showed no elevation of sodium between HS and mannitol. Gu et al. reported high sodium levels by HS [23]. They included studies using high concentration of HS (15\%), which may result in high sodium levels, whereas our meta-analysis did not. We found relatively low concentration of HS (3-7.5\%) might be safely used.

The efficacy of prehospital use of HS is still unclear. ICP is typically measured in the ICU and the evidence

Table 2 Summary of findings

\begin{tabular}{|c|c|c|c|c|c|}
\hline \multirow[t]{2}{*}{ Outcomes } & \multicolumn{2}{|c|}{ Anticipated absolute effects ${ }^{*}(95 \% \mathrm{Cl})$} & \multirow{2}{*}{$\begin{array}{l}\text { Relative effect (95\% } \\
\text { Cl) }\end{array}$} & \multirow{2}{*}{$\begin{array}{l}\text { Number of } \\
\text { participants } \\
\text { (studies) }\end{array}$} & \multirow{2}{*}{$\begin{array}{l}\text { Certainty } \\
\text { of the } \\
\text { evidence } \\
\text { (GRADE) }\end{array}$} \\
\hline & Risk with mannitol & Risk with HS & & & \\
\hline All-cause mortality & 382 per 1000 & $\mathbf{3 1 3}$ per 1000 (187 to 523$)$ & RR $\mathbf{0 . 8 2}$ (0.49 to 1.37$)$ & 105 (3 studies) & Very low \\
\hline 90-days mortality & 500 per 1000 & 270 per 1000 (115 to 635$)$ & RR 0.54 (0.23 to 1.27$)$ & 58 (2 studies) & Very low \\
\hline 180-days mortality & 356 per 1000 & 292 per $\mathbf{1 0 0 0}(160$ to 540$)$ & RR $\mathbf{0 . 8 2}$ (0.45 to 1.52$)$ & 85 (2 studies) & Very low \\
\hline Good neurological outcome & 709 per 1000 & 752 per 1000 (546 to 1000 ) & RR 1.06 (0.77 to 1.47$)$ & 105 (3 studies) & Very low \\
\hline ICP & - & MD 1.9 lower (6.9 lower to 3.1 higher) & - & 58 (2 studies) & Very low \\
\hline Serum sodium levels & - & MD 2.6 higher (2.76 lower to 7.97 higher) & - & 105 (3 studies) & Very low \\
\hline
\end{tabular}

ICP intracranial pressure, $\mathrm{Cl}$ confidence interval, $\mathrm{HS}$ hypertonic saline, $\mathrm{MD}$ mean deviation, RR risk ratio 
regarding the choice of osmotic agent was derived from studies conducted within the ICU setting. A guideline recommended not using HS or mannitol in the prehospital setting to improve neurological outcomes for patients with TBI [25] and we could not include any prehospital studies in this study.

This meta-analysis has several limitations. First, only three RCTs were analyzed for the primary outcome, and those trials had inadequate information regarding ICP changes and small sample sizes. Second, the infusion volumes and concentrations were not uniform across the studies. Third, the participants and healthcare staff were aware of the group assignments in all the included studies, which may have resulted in performance bias. Nevertheless, given the characteristics of the intervention, it would be impossible to conceal the group assignment. Moreover, it is unlikely that this bias would have affected our results, given the use of stratified randomization and objective endpoints. Finally, all included studies were conducted in the ICU setting and included cases without hypovolemia or after hypovolemia normalization. Therefore, well-designed comparative studies are needed to assess these strategies in different situations, such as prehospital resuscitation, and a larger RCT will be required to support our findings.

\section{Conclusions}

Our systematic review and meta-analysis showed no significant difference in the all-cause mortality values associated with HS or mannitol treatment of TBI patients. The certainty of the evidence was considered very low. Current evidence is limited and further studies are warranted to validate our results.

\section{Supplementary information}

Supplementary information accompanies this paper at https://doi.org/10. 1186/s40560-020-00476-X.

Additional file 1: Supplemental file 1. Search Strategies in the systematic review.

Additional file 2: Supplement file 2(a). Forest plot of the 90-day mortality in comparison between $\mathrm{HS}$ and Mannitol group. HS, hypertonic saline; IV, inverse variance. Supplement file 2(b). Forest plot of the 180day mortality in comparison between HS and Mannitol group. HS, hypertonic saline; IV, inverse variance.

Additional file 3: Supplement file 3(a). Funnel plot of the 90-day mortality in comparison between HS and Mannitol group. RR, risk ratio. Supplement file 3(b). Funnel plot of the 180-day mortality in comparison between HS and Mannitol strategy. RR, risk ratio. Supplement file 3(c). Funnel plot of the good neurological outcome in comparison between HS and Mannitol group. RR, risk ratio. Supplement file 3(d). Funnel plot of the ICP in comparison between HS and Mannitol group. MD, mean difference. Supplement file 3(e). Funnel plot of the serum sodium levels in comparison between $\mathrm{HS}$ and Mannitol group. MD, mean difference.

\section{Abbreviations}

TBI: Traumatic brain injury; ICP: Intracranial pressure; HS: Hypertonic saline: ICU: Intensive care unit; JRC: The Japan Resuscitation Council;
RCT: Randomized controlled trial; GRADE: The Grading of Recommendations Assessment, Development and Evaluation; RR: Risk ratio; Cl: Confidence interval

\section{Acknowledgements}

We thank all the members of the JRC Neuroresuscitation Task Force (Yasuhiko Ajimi, Masaaki Iwase, Kyoko Unemoto, Junji Kumasawa, Jun Goto, Hitoshi Kobata, Atsushi Sawamura, Toru Hifumi, Eisei Hoshiyama, Mitsuru Honda, Yasuhiro Norisue, Shoji Matsumoto, Yasufumi Miyake, Takashi Moriya, Tomoaki Yatabe, Kazuma Yamakawa, Sunghoon Yang, Masahiro Wakasugi, Masao Nagayama, Kosaku Kinoshita, and Hiroshi Nonogi) and Editage (www.editage.jp) for English language editing.

\section{Authors' contributions}

All authors were involved in the study design. YM, HS, YK, TF, and HY identified the studies included in the meta-analysis and analyzed the data. YM drafted the manuscript and YK supervised the drafting of the manuscript. All authors were involved in the data interpretation and discussion. All authors read and approved the final manuscript.

\section{Funding}

Funding was provided by the JRC and the Japan Society of Neuroemergencies and Critical Care (JNE), the Japanese Society of Intensive Care Medicine (JSICM), and the Japan Society of Neurosurgical Emergency as Member Societies of the JRC.

Availability of data and materials

The data used for this meta-analysis were obtained from the articles corresponding to references [13-16] in our list of references.

Ethics approval and consent to participate

Not applicable.

Consent for publication

Not applicable.

\section{Competing interests}

The authors declare that they have no conflicts of interest.

\section{Author details}

'Department of Emergency and Critical care Medicine, Juntendo University Urayasu Hospital, 2-1-1 Tomioka, Urayasu, Chiba 279-0021, Japan.

${ }^{2}$ Emergency and Critical Care Center, Japanese Red Cross Musashino Hospital, Musashino, Japan. ${ }^{3}$ Department of Emergency and Critical Care Medicine, Graduate School of Medicine, University of the Ryukyus, Nishihara, Japan. ${ }^{4}$ Department of Emergency and Critical Care Medicine, Jichi Medical University Saitama Medical Center, Saitama, Japan. ${ }^{5}$ Department of Emergency and Critical Care Medicine, Nippon Medical School, Tokyo, Japan.

Received: 9 May 2020 Accepted: 28 July 2020

Published online: 12 August 2020

\section{References}

1. Marmarou A, Anderson RL, Ward JD, Choi SC, Young HF, Eisenberg HM, et al. Impact of ICP instability and hypotension on outcome in patients with severe head trauma. J Neurosurg. 1991;75:S159-65.

2. Mangat HS, Wu X, Gerber LM, Schwarz JT, Fakhar M, Murthy SB, et al. Hypertonic saline is superior to mannitol for the combined effect on intracranial pressure and cerebral perfusion pressure burdens in patients with severe traumatic brain injury. Neurosurgery. 2020;86:221-30.

3. Carney N, Totten AM, O'Reilly C, Ullman JS, Hawryluk GW, Bell MJ, et al. Guidelines for the management of severe traumatic brain injury, fourth edition. Neurosurgery. 2017;80:6-15.

4. Wakai A, McCabe A, Roberts I, Schierhout G. Mannitol for acute traumatic brain injury. Cochrane Database Syst Rev. 2013;8:CD001049.

5. Oddo M, Levine JM, Frangos S, Carrera E, Maloney-Wilensky E, Pascual JL, et al. Effect of mannitol and hypertonic saline on cerebral oxygenation in patients with severe traumatic brain injury and refractory intracranial hypertension. J Neurol Neurosurg Psychiatry. 2009;80:916-20. 
6. Patil H, Gupta R. A comparative study of bolus dose of hypertonic saline, mannitol, and mannitol plus glycerol combination in patients with severe traumatic brain injury. World Neurosurg. 2019;125:e221-8.

7. Harutjunyan L, Holz C, Rieger A, Menzel M, Grond S, Soukup J. Efficiency of $7.2 \%$ hypertonic saline hydroxyethyl starch 200/0.5 versus mannitol 15\% in the treatment of increased intracranial pressure in neurosurgical patients - a randomized clinical trial [ISRCTN62699180]. Crit Care. 2005;9:R530-40.

8. White $H$, Cook $D$, Venkatesh $B$. The use of hypertonic saline for treating intracranial hypertension after traumatic brain injury. Anesth Analg. 2006; 102:1836-46.

9. Japan Medical Abstracts Society. http://search.jamas.or.jp/. Accessed February 14, 2020.

10. Liberati A, Altman DG, Tetzlaff J, Mulrow C, Gøtzsche PC, loannidis JP, et al. The PRISMA statement for reporting systematic reviews and meta-analyses of studies that evaluate health care interventions: explanation and elaboration. J Clin Epidemiol. 2009;62:e1-34.

11. Guyatt G, Oxman AD, Akl EA, Kunz R, Vist G, Brozek J, et al. GRADE guidelines: 1. Introduction-GRADE evidence profiles and summary of findings tables. J Clin Epidemiol. 2011;64:383-94.

12. Higgins JP, Altman DG, Gotzsche PC, Juni P, Moher D, Oxman AD, et al. The Cochrane Collaboration's tool for assessing risk of bias in randomised trials. BMJ. 2011:343:d5928.

13. Vialet R, Albanese J, Thomachot L, Antonini F, Bourgouin A, Alliez B, et al. Isovolume hypertonic solutes (sodium chloride or mannitol) in the treatment of refractory posttraumatic intracranial hypertension: $2 \mathrm{~mL} / \mathrm{kg} 7$. $5 \%$ saline is more effective than $2 \mathrm{~mL} / \mathrm{kg}$ 20\% mannitol. Crit Care Med. 2003:31:1683-7.

14. Francony G, Fauvage B, Falcon D, Canet C, Dilou H, Lavagne P, et al. Equimolar doses of mannitol and hypertonic saline in the treatment of increased intracranial pressure. Crit Care Med. 2008;36:795-800.

15. Cottenceau V, Masson F, Mahamid E, Petit L, Shik V, Sztark F, et al. Comparison of effects of equiosmolar doses of mannitol and hypertonic saline on cerebral blood flow and metabolism in traumatic brain injury. J Neurotrauma. 2011;28:2003-12.

16. Jagannatha AT, Sriganesh K, Devi BI, Rao GS. An equiosmolar study on early intracranial physiology and long term outcome in severe traumatic brain injury comparing mannitol and hypertonic saline. J Clin Neurosci. 2016;27: 68-73.

17. Li M, Chen T, Chen SD, Cai J, Hu YH. Comparison of equimolar doses of mannitol and hypertonic saline for the treatment of elevated intracranial pressure after traumatic brain injury. Medicine. 2015;94:e736.

18. Berger-Pelleiter E, Émond M, Lauzier F, Shields JF, Turgeon AF. Hypertonic saline in severe traumatic brain injury: a systematic review and metaanalysis of randomized controlled trials. CJEM. 2016;18:112-20.

19. Juul N, Morris GF, Marshall SB, Marshall LF. Intracranial hypertension and cerebral perfusion pressure: influence on neurological deterioration and outcome in severe head injury. The Executive Committee of the International Selfotel Trial. J Neurosurg. 2000:92:1-6.

20. Farahvar A, Gerber LM, Chiu YL, Hartl R, Froelich M, Carney N, et al. Response to intracranial hypertension treatment as a predictor of death in patients with severe traumatic brain injury. J Neurosurg. 2011;114:1471-8.

21. Mangat HS, Chiu YL, Gerber LM, Alimi M, Ghajar J, Hartl R. Hypertonic saline reduces cumulative and daily intracranial pressure burdens after severe traumatic brain injury. J Neurosurg. 2015;122:202-10.

22. Schwimmbeck F, Voellger B, Chappell D, Eberhart L. Hypertonic saline versus mannitol for traumatic brain injury: a systematic review and metaanalysis with trial sequential analysis [published online ahead of print, 2019 Sep 20]. J Neurosurg Anesthesiol. 2019;10.1097/ANA.00000000000000644.

23. Gu J, Huang H, Huang Y, Sun $H, X u H$. Hypertonic saline or mannitol for treating elevated intracranial pressure in traumatic brain injury: a metaanalysis of randomized controlled trials. Neurosurg Rev. 2019;42:499-509.

24. Sakellaridis N, Pavlou E, Karatzas S, et al. Comparison of mannitol and hypertonic saline in the treatment of severe brain injuries. J Neurosurg. 2011;114:545-8

25. Cook AM, Morgan Jones G, Hawryluk GWJ, Mailloux P, McLaughlin D, Papangelou A, et al. Guidelines for the acute treatment of cerebral edema in neurocritical care patients. Neurocrit Care. 2020;32:647-66.

\section{Publisher's Note}

Springer Nature remains neutral with regard to jurisdictional claims in published maps and institutional affiliations.

\section{Ready to submit your research? Choose BMC and benefit from:}

- fast, convenient online submission

- thorough peer review by experienced researchers in your field

- rapid publication on acceptance

- support for research data, including large and complex data types

- gold Open Access which fosters wider collaboration and increased citations

- maximum visibility for your research: over $100 \mathrm{M}$ website views per year

At BMC, research is always in progress.

Learn more biomedcentral.com/submissions 